\title{
Meditation and happiness: Mindfulness and self-compassion may mediate the meditation-happiness relationship
}

Campos, Daniel ${ }^{1}$ (camposd@uij.es); Cebolla, Ausiàs ${ }^{1,8}$ (acebolla@uji.es); Quero, Soledad ${ }^{1,8}$ (squero@uji.es); Bretón-López., Juana ${ }^{1,8} \quad$ (breton@uji.es); Botella, Cristina $^{1,8}$ (botella@uij.es); Soler, Joaquim²,3,4 (jsolerri@santpau.cat), García-Campayo, Javier $^{5}$ (jgarcamp@gmail.com); Demarzo, Marcelo (demarzo@unifesp.br); Baños, Rosa María 7,8 (banos@uv.es).

1 Department of Basic Psychology, Clinic and Psychobiology, Universitat Jaume I, (Castellón, Spain)

${ }^{2}$ Department of Psychiatry, Hospital de la Santa Creu i Sant Pau (Barcelona, Spain)

${ }^{3}$ Universitat Autònoma de Barcelona (Barcelona, Spain)

${ }^{4}$ Centre for Biomedical Research in Mental Health (CIBERSAM, Spain)

${ }^{5}$ Universidad de Zaragoza (Zaragoza, Spain)

${ }^{6}$ Universidad Federal de São Paulo (São Paulo, Brasil)

${ }^{7}$ Department of Personality, Evaluation and Psychological Treatment, Universidad de Valencia (Valencia, Spain)

${ }^{8}$ CIBER de Fisiopatología de la Obesidad y Nutrición (CIBEROBN) (Spain)

\section{Address for correspondence:}

Universitat Jaume I, Labpsitec. Av. Sos Baynat s/n, 12071 (Castellón, Spain). Phone: +34964387643

e-mail adress: acebolla@uji.es (Ausiàs Cebolla) 


\section{Abstract}

Mindfulness and self-compassion are emerging as crucial constructs in mental health research. Recent studies have shown that both mindfulness and self-compassion skills may play important roles in well-being and positive emotions associated with mindfulness training. Studies are needed to explain this relationship and to determine what facets may be correlating and mediating the meditation-happiness relationship. The aim of this study was to explore the meditation-happiness relationship and examine which mindfulness and self-compassion facets are better predictors of happiness. A total of 365 participants completed an assessment protocol composed of: the Five Facets of Mindfulness Questionnaire (FFMQ), the Self-Compassion Scaleshort form (SCS-SF), and the Pemberton Happiness Index (PHI). Hierarchical regression analysis showed that two FFMQ facets (Observing and Awareness) and two SCS components (Self-kindness and Common humanity) were significant predictors of happiness. Mediation results revealed a significant total indirect effect of Observing, Awareness, Self-kindness and Common humanity in the meditation frequencyhappiness relationship. Significant indirect effects were found for observing, selfkindness and common humanity. The results supported the model of mindfulness and self-compassion facets as partial mediators of the meditation-happiness relationship. Findings are in line with other studies and provide evidence about the influence of mindfulness and self-compassion on happiness.

Keywords: Mindfulness, meditation, self-compassion, positive psychology, happiness. 


\section{Introduction.}

Mindfulness refers to the self-regulation of attention to one's experiences in the present moment with curiosity, openness and acceptance (Bishop et al., 2004). It can also be understood as a disposition, trait or stable tendency to be mindful in everyday life (Brown \& Ryan, 2003). Dispositional mindfulness has been shown to be related to less perceived stress (Tran et al., 2014), fewer depressive and anxiety symptoms (Tejedor et al., 2014) or acceptance of pain (Cebolla, Luciano, Demarzo, Navarro-Gil \& García-Campayo, 2013). Moreover, the tendency to be mindful can be increased through different methods, such as the practice of meditation and clinical treatments using mindfulness-based interventions (MBI), which have been shown to be efficient in the treatment of many psychological disorders (Khoury et al., 2013).

Although numerous studies have analyzed the relationship between mindfulness and psychological symptoms in several mental disorders, the relationship between mindfulness and positive psychological variables has been researched less. So far, mindfulness has been related to positive emotions (Fredrickson, Cohn, Coffey, Pek \& Finkel, 2008), positive reappraisal (Hanley \& Garland, 2014), life satisfaction (Kong, Wang \& Zhao, 2014), psychological health (Keng, Smoski \& Robins, 2011), and psychological well-being (Baer et al., 2008; Brown \& Ryan, 2003). Mindfulness has been associated with self-compassion, which has been defined as "being touched by and open to one's own suffering, not avoiding or disconnecting from it, generating the desire to alleviate one's suffering and to heal oneself with kindness" (Neff, 2003a, p. 87). Neff (2003 a, b) suggests a reciprocal relationship between mindfulness and selfcompassion where they facilitate and enhance each other. According to this author, self-compassion entails three main components that overlap and mutually interact: Self-kindness versus self-judgment, feelings of common humanity versus isolation, and

mindfulness versus over-identification. Other authors also point out that selfcompassion is an essential skill in order to be mindful (Kabat-Zinn, 2003; Shapiro, 
Astin, Bishop \& Cordova, 2005). Compassion could arise naturally with mindfulness; understanding the ubiquity of suffering and the deep connection shared with other living beings makes us inclined to feel others' pain and wish them well, just as we wish to be well (Hollis-Walker \& Colosimo, 2011). These attitudes of gentleness in one's private and public behaviors are commonly promoted in various $\mathrm{MBI}$. Evidence suggests that self-compassion may be an especially important component of the positive mental states associated with MBls. Along these lines, Kuyken et al. (2010) report that increases in mindfulness and self-compassion across treatment mediate the effect of MBI on depressive symptoms.

Research shows that each of these two constructs seems to be independently related to well-being (e.g., Baer et al., 2008; Chang, Huang \& Lin, 2014; Neff, 2011). The self-compassion trait has been related to fewer symptoms of depression (Krieger, Altenstein, Baettig, Grosse \& Holtforth, 2013), anxiety (Neff, Kirkpatrick \& Rude, 2007), burn-out (Woo, 2013), psychological distress and perceived stress (Shapiro et al., 2005), severity of quality of life and worry (Van Dam, Sheppard, Forsyth \& Earleywine, 2011). Van Dam et al. (2011) found that self-compassion is a better predictor than mindfulness of symptoms and quality of life in mixed anxiety and depression. However, few studies have included measures of both mindfulness and self-compassion and their relationship with well-being or happiness (Baer, Lykins \& Peters, 2012; HollisWalker \& Colosimo, 2011).

Happiness has been conceptualized based on two general approaches: hedonic and eudaimonic. Hedonism refers to the importance of life satisfaction and affective components like positive emotions, whereas eudaimonic well-being is focused on optimal psychological functioning, which depends on self-fulfillment and includes the concepts of personal growth, purpose in life, and a sense of autonomy, among others (Hervás \& Vázquez, 2013, Ryff \& Keyes, 1995; Ryan \& Deci, 2001). Recent western literature and Buddhist philosophy further emphasize the role of mindfulness and self- 
compassion in happiness (Germer, 2009; Gilbert, 2010; Rahula, Rahula \& Demieville, 2007). Hollis-Walker and Colosimo (2011) found that mindfulness is related to psychologically adaptive variables, and that self-compassion is a crucial attitudinal factor in the mindfulness-happiness relationship. However, there is no literature about the way these two concepts are related to happiness and how the practice of meditation interacts with them.

Baer et al. (2012) found that both mindfulness and self-compassion skills improved well-being associated with mindfulness training in a sample of meditators, and both are important in predicting psychological well-being. Mindfulness and self-compassion total scores mediated the relationship between meditation experience and well-being. When mindfulness and self-compassion facets were included, results showed a final model composed of "Common humanity/mindfulness" from the Self-Compassion Scale (SCS) and "Describing and nonjudging/nonreactivity" from the Five Facets Mindfulness Questionnaire (FFMQ; Baer, Smith, Hopkins, Krietemeyer, \& Toney, 2006) as significant independent predictors of well-being. However, in their study, Baer et al. (2012) did not include the influence of the frequency of mindfulness practice, a relevant concept because the tendency to be mindful in daily life is affected by how often one practices it (Soler, Cebolla et al., 2014). In fact, according to Schoormans and Nyklíček (2011), the frequency of meditation practice is a better predictor of well-being than the type of meditation.

Therefore, the purpose of this study is to examine whether meditation frequency is related to happiness, and whether dispositional mindfulness and self-compassion could be mediating this relationship. The specific hypotheses are: a) both mindfulness and self-compassion facets are significantly correlated with meditation frequency and happiness; b) participants with high meditation practice frequency have higher levels of mindfulness, self-compassion and happiness, versus non-meditators; and c) 
Mindfulness and self-compassion facets mediate the association between the frequency of meditation practice and happiness scores.

\section{Method}

\subsection{Participants and procedure}

Participants completed an assessment protocol via a commercial online survey system (www.surveymonkey.com). A link to this protocol was posted on several Spanish websites about mindfulness, meditation and psychology (scientific associations, mindfulness associations, monasteries, etc.), as well as on nonprofessional social networks (i.e., Facebook). A total of 599 subjects accessed the website, 487 voluntarily agreed to participate, and 365 completed the survey and made up the final sample (183 meditators vs 182 non-meditators).

\subsection{Measures}

\subsubsection{Socio-demographic and meditation frequency information}

Socio-demographic data were obtained regarding age, sex and education. Meditation frequency was assessed with a brief questionnaire specifically designed for this study. Participants reported whether they meditated every day, 3 or 4 times a week, once a week or less, or never.

\subsubsection{Dispositional Mindfulness}

The mindfulness trait was evaluated with the Five Facets of Mindfulness Questionnaire (FFMQ; Baer et al., 2006; Cebolla et al., 2012). The FFMQ is a questionnaire for measuring dispositional mindfulness. It consists of 39 items rated on a Likert scale ranging from 1 (never or very rarely true) to 5 (very often or always true). These items measure a personal disposition to being mindful in daily life, focusing on five factors of mindfulness: Observe, refers to the subject's capacity to pay attention to internal and external experiences such as sensations, thoughts, or emotions; Describe, 
measures the ability to describe events and personal responses in words; Acting with awareness, includes focusing on the activity being carried out, as opposed to behaving automatically; Non-judging of inner experience, refers to the ability to take a nonevaluative stance toward thoughts and feelings; Non-reactivity to inner experience, allowing thoughts and feelings to come and go, without getting caught up in them or carried away by them (Baer et al., 2008). The five scales show good internal consistency. In the present sample, the alpha was .93 for the total score and ranged from .85 to .93 for the subscales (observe, $\alpha=.85$; describe, $\alpha=.90$; awareness, $\alpha=.91$; non-judging, $\alpha=.93$; non-reactivity, $\alpha=.85$ ).

\subsubsection{Self-compassion}

Self-compassion was measured using the short form of the Self-Compassion Scale (SCS) (Neff, 2003 a, b; García-Campayo et al., 2014). Items are rated on a Likert scale ranging from 1 (almost never) to 5 (almost always). The Self-Compassion Scaleshort form (SCS-SF) is a 12-item questionnaire designed to assess overall selfcompassion (total score) and three self-compassion facets: self-kindness (SCS-SK), common humanity (SCS-CH) and mindfulness (SCS-M). The Spanish version of the SCS-SF has shown high internal consistency and high test-retest reliability. In the present sample, the alpha was .79 for SCS-SK, $\alpha=.60$ for SCS-CH and $\alpha=.74$ for SCSM.

\subsubsection{Happiness}

Happiness was assessed with the Pemberton Happiness Index (PHI; Hervás \& Vázquez, 2013). PHI is a measure of well-being. The scale contains eleven items related to different domains of remembered well-being and ten items related to experienced well-being (i.e., positive and negative emotional events that might have happened the day before). The sum of these items produces a combined well-being index. In the sample used for the present study, the alpha coefficient was .87. 


\subsection{Statistical Analysis}

Analyses of Variance (ANOVA) and chi-squared tests were used to examine socio-demographic differences between groups according to their frequency of meditation. Correlations analysis was performed to explore the relationships among the mindfulness and self-compassion facets, happiness scores and frequency of meditation. A multivariate analysis of covariance (MANCOVA), adjusting for age, was applied to compare mean differences in mindfulness and self-compassion facets, considering the different groups of frequency of meditation (from daily to never). In the same way, analysis of covariance (ANCOVA) was used to assess the differences in happiness scores, adjusting for age. A step-wise hierarchical regression analysis was conducted to examine the facets that predict happiness. To test the hypothesis that mindfulness and self-compassion mediate the meditation-happiness relationship, a bootstrap regression analysis was carried out using the Preacher and Hayes (2004) approach.

\section{Results}

First, ANOVA analysis applied to the socio-demographic variables revealed significant differences for age; therefore, age differences were taken into account in subsequent analyses. No differences were found for sex or level of education. Table 1 shows the descriptive data regarding frequency of meditation.

\section{INSERT TABLE 1}

Correlations analyses were conducted for the frequency of meditation practice, dispositional mindfulness (FFMQ), self-compassion (SCS-SF) and happiness (PHI) (Table 2). Results showed that the mindfulness and self-compassion scales were positively and significantly correlated with the happiness measure. Furthermore, as 
expected, frequency of meditation was positively and significantly correlated with the mindfulness scales, the self-compassion scales and happiness $(r=.222 ; p<.01)$.

\section{INSERT TABLE 2}

Multivariate analyses of covariance (MANCOVA) were conducted to test differences between frequency of meditation and the mindfulness and self-compassion scales. The MANCOVA results, adjusting for age, showed significant differences between groups (frequency of meditation) on all the mindfulness scales $([F(15$, 1074)=9.227; $\left.\left.\quad p<.001 ; \quad \eta_{p}^{2}=.11\right]\right)$ : Observing $\left[F(3,360)=29.184 ; \quad p<.001 ; \quad \eta_{p}^{2}=.20\right]$, describing $\left[F(3,360)=6.344 ; p<.001 ; \eta_{p}^{2}=.05\right]$, acting with awareness $[F(3,360)=4.348$; $\left.p<.01 ; \eta_{p}^{2}=.04\right]$, non judging inner experience $\left[F(3,397)=16.106 ; p<.001 ; \eta_{p}^{2}=.12\right]$ and non reactivity to inner experience $\left[F(3,360)=27.820 ; p<.001 ; \eta_{p}^{2}=.19\right]$. Regarding the self-compassion scales, again there were significant differences between frequencies of meditation and $\quad\left(\left[F(9, \quad 1080)=8.439 ; \quad p<.001 ; \quad \eta_{p}^{2}=.07\right]\right): \quad$ Selfkindness $\left[F(3,360)=19.095 ; \quad p<.001 ; \eta_{p}^{2}=.14\right]$, common humanity $[F(3,360)=15.011$; $\left.p<.001 ; \quad \eta_{p}^{2}=.11\right]$ and mindfulness $\left[F(3,360)=23.145 ; \quad p<.001 ; \eta_{p}{ }^{2}=.16\right]$. Post hoc Bonferroni analyses were applied (see Table 3). For both measures, mindfulness and self-compassion, age was not a significant covariant ( $p>.05)$.

ANCOVA analysis, adjusting for age, also showed statistically significant differences in happiness scores $\left(\left[F(3,360)=6.114 ; p<.01 ; \eta_{p}{ }^{2}=.05\right]\right)$. The daily (D) meditation group scored significantly higher than the group that never practices meditation (see Table 3). No differences were found between the other groups. Furthermore, age was not found to be a significant covariant $([F(1,360)=.260 ; p>.05$; $\left.\left.\eta_{p}^{2}=.001\right]\right)$

\section{INSERT TABLE 3}

Next, we examined which facets predict happiness, using a stepwise hierarchical regression analysis. Educational level and age were entered in Step 1. In Step 2, the 
FFMQ and SCS subscales were entered simultaneously. Only two factors from the mindfulness scale (Observe and Awareness) and two SCS components (Self-kindness and Common humanity) remained significant predictors of happiness. Table 4 shows the significant predictors included in the final model obtained.

\section{INSERT TABLE 4}

Finally, the mediation results from the bootstrapping analysis are shown in Figure 1. In our proposed mediation model, we included only the subscales of the FFMQ and SCS that were shown to be significant predictors of happiness in the previous regression analysis. Observing and awareness (mindfulness facets) and self-kindness and common humanity (SCS subscales) were entered as mediators in the relationship between frequency of meditation and happiness.

\section{INSERT FIGURE 1}

The total indirect effect via observing, awareness, self-kindness and common humanity was significant (95\% bootstrap confidence interval of 0.233-0.405). Significant indirect effects were found for observing (95\% bootstrap confidence interval of $0.033-0.161)$, self-kindness (95\% bootstrap confidence interval of $0.089-0.184$ ) and common humanity (95\% bootstrap confidence interval of $0.049-0.142)$. No significant indirect effects were observed for awareness (95\% bootstrap confidence interval of (0.000-0.041). The results suggest that observing, self-kindness and common humanity were significant independent components of the effect of meditation frequency on happiness. Bootstrap regression analysis supported the model of mindfulness (observing) and self-compassion (self-kindness and common humanity) as partial mediators in the meditation-happiness relationship. 


\section{Discussion}

The aim of this study is to examine how meditation frequency (from daily to non practice) is related to greater happiness, and how dispositional mindfulness and selfcompassion could be mediating this relationship. As expected in our first hypothesis, the frequency of meditation practice is related to the levels of dispositional mindfulness, self-compassion and happiness. These findings are similar to previous studies showing that both concepts are related to well-being (e.g., Baer et al., 2012; Hollis-Walker \& Colosimo, 2011). In addition, results are in line with those expected in the second hypothesis, as groups with high meditation frequency have higher levels of mindfulness, self-compassion and happiness.

Regarding the third hypothesis, we tested the hypothesis that dispositional mindfulness and self-compassion facets could be mediating the association between the frequency of meditation practice and happiness scores. The results obtained confirmed this hypothesis; the facets of mindfulness observing and awareness and the self-compassion facets self-kindness and common humanity were significant predictors of happiness. However, when they were all introduced in the mediation model, only observing, self-kindness and common humanity continued to be partial mediators between frequency of meditation and happiness.

These results differ from those found by Baer et al. (2012) suggesting common humanity/mindfulness (self-compassion facets) and describing and nonjudging/nonreactivity (mindfulness facets) as significant independent predictors of well-being. As pointed out by Baer et al. (2012), it is possible that in other samples, the specific subscales showing incremental validity in the prediction of well-being might differ from those reported in their study. Furthermore, other methodological aspects of our study differ from Baer et al. (2012), as a larger sample of participants is used in this study, and the meditation variable we used was meditation frequency versus 
meditation experience in Baer et al. (2012). As mentioned above, meditation frequency was shown to be a great predictor of well-being (Schoormans \& Nyklíček (2011). Regarding the mindfulness and self-compassion facets used to predict and mediate well-being, Baer et al. (2012) used a reduced number of predictors by creating composite variables from pairs of subscales with intercorrelations over 0.50 , whereas in the present study the three self-compassion facets (self-kindness, common humanity and mindfulness) and the five facets of mindfulness (observe, describe, acting with awareness, non-judging and non-reactivity) were used. In this sense, Hollis-Walker and Colosimo (2011) showed that each mindfulness facet significantly predicted psychological well-being, although acting with awareness and describing experiences were the strongest predictors. However, it should be highlighted that their study was carried out in a sample of non-meditators.

Regarding which facet is a better predictor of well-being (Baer et al., 2012; Van Dam et al., 2011), results showed that both the mindfulness and self-compassion facets were similar predictors of happiness, agreeing with Baer et al. (2012). However, in the tested mediational model, self-kindness and common humanity show greater effects on happiness than the mindfulness facet observing, as pointed out by Van Dam et al. (2011), who reported that self-compassion was a stronger predictor than mindfulness of symptoms of anxiety and depression in a clinical non-meditating sample.

From a theoretical point of view, our findings are related to the Bishop et al. (2004) mindfulness definition. Bishop et al. (2004) proposed a two-component model of mindfulness: 1) The self-regulation of attention, so that it is maintained on immediate experience; 2) adopting a particular orientation toward one's experiences in the present moment, an orientation characterized by curiosity, openness, and acceptance. The first component of the definition is represented by the Observing facet, and the second by 
the self-compassion factor, and both (according to the results obtained in this study) seem to mediate the meditation-happiness relationship.

Observing seems to be one of the facets that is most related to and influenced by meditative practice (Lilja, Lundh, Josefsson \& Falkenström, 2013; Soler, Cebolla et al., 2014). However, authors found that this mindfulness facet does not seem to be adequate for assessing mindfulness in individuals without meditation experience (Aguado et al., 2015). Separate analyses of meditator and non-meditator samples should be carried out in order to explore and confirm these results.

Furthermore, our analysis also indicates that the mindfulness and self-compassion facets show partial mediation. In fact, other variables could be mediating this relationship, such as de-centering (Soler, Franquesa et al., 2014), insight (Harrington, Loffredo \& Perz, 2014), life goals (Crane, Winder, Hargus, Amarasinghe \& Barnhofer, 2012), type of meditation (Schoormans \& Nyklíček, 2011), spirituality and religiosity (Chavers, 2013) or personality traits (Giluk, 2009). In future studies, other related factors may be considered as positive predictors of psychological well-being or happiness.

The strong points of the present study are, first, that it is the first study to examine the meditation-happiness relationship in a non-meditator and meditator sample. Second, the use of a large sample of meditators and a direct measure of happiness that covers its different domains (i.e., general, hedonic, eudaimonic, and social) through different assessment approaches (i.e., remembered and experienced wellbeing) (Hervás \& Vázquez, 2013) provides an improvement in this field of knowledge.

Finally, several limitations and methodological issues should be mentioned. First, the sample was recruited over the Internet, which could have resulted in a selection bias regarding the underrepresentation of specific groups of people or meditation types, and it has been previously reported that different types of meditation interact 
differently with the facets of mindfulness (Lippelt, Hommel \& Colzato, 2014). Furthermore, years of meditation practice were not taken into account to test our hypotheses. In addition, given the cross-sectional design of the study, causal inferences were not possible.

In summary, this study provides evidence about the meditation-happiness relationship and how dispositional mindfulness and self-compassion mediate in it. However, there are still outstanding issues. These results could have implications related to theoretical and practical issues. For example, new treatment programs could be designed taking into account the combination of these aspects because selfcompassion training is not included in most of the MBIs. Future studies are needed to provide clear evidence in order to draw stronger conclusions. 


\section{References}

Aguado, J, Luciano, J.V., Cebolla, A., Serrano-blanco, A., Soler, J., \& GarcíaCampayo, J. (2015) Bifactor analysis and construct validity of the Five Facet Mindfulness Questionnaire (FFMQ) in non-clinical Spanish samples. Frontiers in Psychology, 6, 404. doi:10.3389/fpsyg.2015.00404.

Baer, R. A., Lykins, E. L., \& Peters, J. R. (2012). Mindfulness and self-compassion as predictors of psychological wellbeing in long-term meditators and matched nonmeditators. The Journal of Positive Psychology, 7(3), 230-238. http://dx.doi.org/10.1080/17439760.2012.674548.

Baer, R. A., Smith, G. T., Hopkins, J., Krietemeyer, J., \& Toney, L. (2006). Using selfreport assessment methods to explore facets of mindfulness. Assessment, 13, 27-45. doi: 10.1177/1073191105283504.

Baer, R. A., Smith, G. T., Lykins, E., Button, D., Krietemeyer, J., Sauer, S., ... \& Williams, J. M. G. (2008). Construct validity of the five facet mindfulness questionnaire in meditating and non meditating samples. Assessment, 15, 329342. doi: $10.1177 / 1073191107313003$.

Bishop, S. R., Lau, M., Shapiro, S., Carlson, L., Anderson, N. D., Carmody, J., ... \& Devins, G. (2004). Mindfulness: A proposed operational definition. Clinical Psychology: Science and Practice, 11, 230-241. doi:10.1093/clipsy/bph077.

Brown, K. W., \& Ryan, R. M. (2003). The benefits of being present: mindfulness and its role in psychological well-being. Journal of personality and social psychology, 84(4), 822. doi: 10.1037/0022-3514.84.4.822.

Cebolla, A., García-Palacios, A., Soler, J., Guillen, V., Baños, R., \& Botella, C. (2012). Psychometric properties of the Spanish validation of the Five Facets of Mindfulness Questionnaire (FFMQ). The European Journal of Psychiatry, 26(2), 118-126. 
Cebolla, A., Luciano, J. V., Demarzo, M. P., Navarro-Gil, M., \& García-Campayo, J. (2013). Psychometric properties of the Spanish version of the mindful attention awareness scale (MAAS) in patients with fibromyalgia. Health Qual Life Outcomes, 11(6). doi:10.1186/1477-7525-11-6.

Chang, J. H., Huang, C. L., \& Lin, Y. C. (2014). Mindfulness, Basic Psychological Needs Fulfillment, and Well-Being. Journal of Happiness Studies, 1-14. doi: 10.1007/s10902-014-9551-2.

Chavers, D. J. (2013). Relationships between spirituality, religiosity, mindfulness, personality, and resilience. University of South Alabama.

Fredrickson, B. L., Cohn, M. A., Coffey, K. A., Pek, J., \& Finkel, S. M. (2008). Open hearts builds lives: positive emotions, induced through loving-kindness meditation, build consequential personal resources. Journal of Personality and Social Psychology, 95, 1045-1062. http://dx.doi.org/10.1037/a0013262.

García-Campayo, J., Navarro-Gil, M., Andrés, E., Montero-Marin, J., López-Artal, L. y Demarzo, M. (2014). Validation of the Spanish versions of the long (26 items) and short (12 items) forms of the Self-Compassion Scale (SCS). Health and Quality of Life Outcomes, 12(9). doi:10.1186/1477-7525-12-4.

Germer, C. K. (2009). The mindful path to self-compassion: Freeing yourself from destructive thoughts and emotions. New York, NY: Guilford Press.

Gilbert, P. (2010). Compassion focused therapy: Distinctive features. New York, NY: Routledge/Taylor \& Francis Group

Giluk, T. L. (2009). Mindfulness, Big Five personality, and affect: A metaanalysis. Personality and Individual Differences, 47(8), 805-811. doi:10.1016/j.paid.2009.06.026.

Hanley, A. W., \& Garland, E. L. (2014). Dispositional Mindfulness Co-varies with SelfReported Positive Reappraisal. Personality and Individual Differences, 66, 146152. http://doi.org/10.1016/j.paid.2014.03.014 
Harrington, R., Loffredo, D. A., \& Perz, C. A. (2014). Dispositional mindfulness as a positive predictor of psychological well-being and the role of the private selfconsciousness insight factor. Personality and Individual Differences, 71, 15-18. http://dx.doi.org/10.1016/j.paid.2014.06.050.

Hervás, G., \& Vázquez, C. (2013). Construction and validation of a measure of integrative well-being in seven languages: The Pemberton Happiness Index. Health and Quality of Life Outcomes, 11 (66), 1-13. doi:10.1186/1477-7525-1166.

Hollis-Walker, L., \& Colosimo, K. (2011). Mindfulness, self-compassion, and happiness in non-meditators: A theoretical and empirical examination. Personality and Individual Differences, 50(2),

222-227. http://doi.org/10.1016/i.paid.2010.09.033.

Kabat-Zinn, J. (2003). Mindfulness-based interventions in context: Past, present, and future. Clinical Psychology: Science and Practice, 10, 144-156. doi: 10.1093/clipsy/bpg016.

Keng, S. L., Smoski, M. J., \& Robins, C. J. (2011). Effects of mindfulness on psychological health: A review of empirical studies. Clinical psychology review,31(6), 1041-1056. doi:10.1016/j.cpr.2011.04.006.

Kong, F., Wang, X., \& Zhao, J. (2014). Dispositional mindfulness and life satisfaction: The role of core self-evaluations. Personality and Individual Differences, 56, 165-169. http://doi.org/10.1016/i.paid.2013.09.002.

Krieger, T., Altenstein, D., Baettig, I., Doerig, N., \& Holtforth, M. G. (2013). SelfCompassion in Depression: Associations With Depressive Symptoms, Rumination, and Avoidance in Depressed Outpatients. Behavior Therapy, 44(3), 501-513. http://doi.org/10.1016/i.beth.2013.04.004.

Kuyken, W., Watkins, E., Holden, E., White, K., Taylor, R. S., Byford, S., ... Dalgleish, T. (2010). How does mindfulness-based cognitive therapy work? Behaviour 
$\begin{array}{lll}\text { Research } \quad \text { and } \quad \text { Therapy, } & \text { 111), }\end{array}$ http://doi.org/10.1016/j.brat.2010.08.003

Lilja, J. L., Lundh, L. G., Josefsson, T., \& Falkenström, F. (2013). Observing as an essential facet of mindfulness: a comparison of $F F M Q$ patterns in meditating and non-meditating individuals. Mindfulness, 4(3), 203-212. doi; $10.1007 / \mathrm{s} 12671-012-0111-8$.

Lippelt, D. P., Hommel, B., \& Colzato, L. S. (2014). Focused attention, open monitoring and loving kindness meditation: effects on attention, conflict monitoring, and creativity - A review. Frontiers in Psychology, 5. http://doi.org/10.3389/fpsyg.2014.01083.

Neff, K. D. (2011). Self-compassion, self-esteem, and well-being. Social and personality psychology compass, 5(1), 1-12. doi: 10.1111/j.17519004.2010.00330.x.

Neff, K. D., Kirkpatrick, K. L., \& Rude, S. S. (2007). Self-compassion and adaptive psychological functioning. Journal of Research in Personality, 41(1), 139-154. http://doi.org/10.1016/j.jrp.2006.03.004.

Neff, K.D. (2003a). Self-compassion: an alternative conceptualization of a healthy attitude towards oneself. Self Identity, 2, 85-101. doi: $10.1080 / 15298860309032$.

Neff, K.D. (2003b). The development and validation of a scale to measure selfcompassion. Self Identity, 2, 223-250. doi: 10.1080/15298860309027.

Rahula, W., Rahula, W., \& Demieville, P. (2007). What the Buddha Taught: Revised And. Grove Press.

Ryan, R. M., \& Deci, E. L. (2001). On happiness and human potentials: A review of research on hedonic and eudaimonic well-being. Annual review of psychology, 52(1), 141-166. doi: 10.1146/annurev.psych.52.1.141. 
Ryff, C. D., \& Keyes, C. L. M. (1995). The structure of psychological well-being revisited. Journal of personality and social psychology,69(4), 719. http://dx.doi.org/10.1037/0022-3514.69.4.719.

Schoormans, D., \& Nyklíček, I. (2011). Mindfulness and psychological well-being: are they related to type of meditation technique practiced?. The journal of alternative and complementary medicine, 17(7), 629-634. doi:10.1089/acm.2010.0332.

Shapiro, S. L., Astin, J. A., Bishop, S. R., \& Cordova, M. (2005). Mindfulness-based stress reduction for health care professionals: results from a randomized trial. International Journal of Stress Management, 12(2), 164-176. http://dx.doi.org/10.1037/1072-5245.12.2.164.

Soler, J., Cebolla, A., Feliu-Soler, A., Demarzo, M. M., Pascual, J. C., Baños, R., \& García-Campayo, J. (2014). Relationship between meditative practice and selfreported mindfulness: the MINDSENS composite index. PloS one,9(1), e86622. doi: $10.1371 /$ journal.pone.0086622.

Soler, J., Franquesa, A., Feliu-Soler, A., Cebolla, A., García-Campayo, J., Tejedor, R., ... \& Portella, M. J. (2014). Assessing Decentering: Validation, Psychometric Properties, and Clinical Usefulness of the Experiences Questionnaire in a Spanish Sample. Behavior therapy, 45(6), 863-871.

Tejedor, R., Feliu-Soler, A., Pascual, J. C., Cebolla, A., Portella, M. J., Trujols, J., ... \& Soler, J. (2014). Propiedades psicométricas de la versión española de la Philadelphia Mindfulness Scale. Revista de Psiquiatría y Salud Mental, 7(4), 157-165. doi: 10.1016/j.rpsm.2014.04.001.

Tran, U. S., Cebolla, A., Glück, T. M., Soler, J., Garcia-Campayo, J., \& von Moy, T. (2014). The Serenity of the Meditating Mind: A Cross-Cultural Psychometric Study on a Two-Factor Higher Order Structure of Mindfulness, Its Effects, and Mechanisms Related to Mental Health among Experienced Meditators. PloS one, 9(10), e110192. doi: 10.1371/journal.pone.0110192. 
Van Dam, N.T., Sheppard, S.C., Forsyth, J.P., \& Earleywine, M. (2011). Selfcompassion is a better predictor than mindfulness of symptom severity and quality of life in mixed anxiety and depression. Journal of Anxiety Disorders, 25, 123-130. doi: 10.1016/j.janxdis.2010.08.011.

Woo Kyeong, L. (2013). Self-compassion as a moderator of the relationship between academic burn-out and psychological health in Korean cyber university students. Personality and Individual Differences, 54(8), 899-902. http://doi.org/10.1016/i.paid.2013.01.001 
Table 1. Socio-demographic characteristics.

\begin{tabular}{|c|c|c|c|c|c|c|}
\hline & \multicolumn{4}{|l|}{ Mean (SD) } & \multirow[t]{2}{*}{$\boldsymbol{F}$} & \multirow[t]{2}{*}{$p$} \\
\hline & Daily & $\begin{array}{c}3 \text { or } 4 \text { times } \\
\text { a week }\end{array}$ & $\begin{array}{c}\text { Once a week } \\
\text { or less }\end{array}$ & Never & & \\
\hline & $\mathrm{N}=89$ & & & $\mathrm{~N}=182$ & & \\
\hline & & $\mathrm{N}=61$ & $\mathrm{~N}=33$ & & & \\
\hline Age & $44.94(9.7)$ & $42.9(10.16)$ & $44.27(11.81)$ & $39.58(11.55)$ & 5.730 & $<.05$ \\
\hline Sex & & & & & $X^{2}$ & $p$ \\
\hline Male & $33(37.1 \%)$ & $24(39.3 \%)$ & $11(33.3 \%)$ & $50(27.5 \%)$ & & \\
\hline Female & $56(62.9 \%)$ & 37 (60.7\%) & $22(66.7 \%)$ & $132(72.5 \%)$ & 4.267 & n.s. \\
\hline Education & & & & & & \\
\hline Primary studies & $1(1.1 \%)$ & - & - & $2(1.1 \%)$ & & \\
\hline Secondary studies & $12(13.8 \%)$ & $3(4.9 \%)$ & $1(3 \%)$ & $13(7.1 \%)$ & & \\
\hline University & $76(85.1 \%)$ & $58(95.1 \%)$ & $32(97.0 \%)$ & $167(91.8 \%)$ & 10.992 & n.s \\
\hline
\end{tabular}


Table 2. Correlations of mindfulness and self-compassion scales with frequency of meditation and happiness.

\begin{tabular}{lcc}
\hline & $\begin{array}{c}\text { Frequency of } \\
\text { Meditation }\end{array}$ & Happiness \\
\hline Mindfulness Scales & $.445^{\star *}$ & $.387^{\star *}$ \\
Observing & $.210^{\star *}$ & $.398^{\star *}$ \\
Describing & $.137^{\star *}$ & $.347^{\star *}$ \\
Acting with awareness & $.327^{\star *}$ & $.391^{\star *}$ \\
Non-judging & $.442^{\star *}$ & $.499^{\star *}$ \\
Non-reactivity & $.441^{\star *}$ & $.555^{\star *}$ \\
FFMQ total score & $.377^{\star *}$ & $.598^{\star *}$ \\
Self-compassion scales & $.344^{\star *}$ & $.558^{\star *}$ \\
Self-kindness & $.421^{\star *}$ & $.546^{\star *}$ \\
Common humanity & $.424^{\star *}$ & $.630^{\star *}$ \\
Mindfulness & $.222^{\star *}$ & - \\
SCS total score & & \\
Happiness & &
\end{tabular}


Table 3. MANCOVA and ANCOVA.

\begin{tabular}{|c|c|c|c|c|c|c|c|c|c|}
\hline & \multicolumn{5}{|c|}{ Mindfulness facets } & \multicolumn{3}{|c|}{ Self-compassion scales } & \multirow[t]{2}{*}{ Happiness } \\
\hline & Observing & Describing & $\begin{array}{l}\text { Acting with } \\
\text { awareness }\end{array}$ & Non-judging & $\begin{array}{l}\text { Non- } \\
\text { reactivity }\end{array}$ & $\begin{array}{c}\text { Self- } \\
\text { kindness }\end{array}$ & $\begin{array}{l}\text { Common } \\
\text { humanity }\end{array}$ & Mindfulness & \\
\hline D & $\begin{array}{c}30.92(4.13) \\
{[56-60]}\end{array}$ & $\begin{array}{l}32.65(4.91) \\
{[55.4-59.3]}\end{array}$ & $\begin{array}{l}29.80(4.85) \\
{[47.8-51.7]}\end{array}$ & $\begin{array}{c}33.55(5.15) \\
{[48.4-52.3]}\end{array}$ & $\begin{array}{c}26.38(3.45) \\
{[59-63]}\end{array}$ & $\begin{array}{c}4.01(.58) \\
{[45.7-49.71}\end{array}$ & $\begin{array}{c}3.86(.66) \\
{[49-53]}\end{array}$ & $\begin{array}{l}3.96(.60) \\
{[48.1-52]}\end{array}$ & $\begin{array}{c}8.18(.13) \\
{[62.4-66.4]}\end{array}$ \\
\hline $3-4 \mathrm{~T}$ & $29.59(4.95)$ & $31.95(5.46)$ & $27.47(5.69)$ & $32.13(6.77)$ & $24.63(4.16)$ & $3.77(.77)$ & $3.62(.79)$ & $3.87(.72)$ & $7.88(.15)$ \\
\hline OW & $\begin{array}{l}{[44.3-48.3]} \\
27.51(5.11)\end{array}$ & $\begin{array}{l}{[44.8-49.8]} \\
31.61(4.50)\end{array}$ & $\begin{array}{l}{[36.4-40.3]} \\
26.36(5.17)\end{array}$ & $\begin{array}{l}{[38.4-42.3]} \\
32.90(5.85)\end{array}$ & $\begin{array}{l}{[45.7-49.6]} \\
23.00(3.43)\end{array}$ & $\begin{array}{c}{[35.6-39.6]} \\
3.79(.73)\end{array}$ & $\begin{array}{c}{[38.1-42.1]} \\
3.75(.57)\end{array}$ & $\begin{array}{c}{[39.1-43.1]} \\
3.59(.80)\end{array}$ & $\begin{array}{c}{[49.9-53.9]} \\
7.81(.21)\end{array}$ \\
\hline $\mathrm{N}$ & $\begin{array}{l}{[29.2-33.2]} \\
25.26(5.34) \\
{[65.5-69.4]}\end{array}$ & $\begin{array}{c}{[32.1-36]} \\
29.94(5.61) \\
{[72.8-76.7]}\end{array}$ & $\begin{array}{c}{[25-29]} \\
27.55(5.93) \\
{[63.9-67.9]}\end{array}$ & $\begin{array}{c}{[28.4-32.3]} \\
28.35(6.53) \\
{[59-62.9]}\end{array}$ & $\begin{array}{l}{[30.7-34.6]} \\
21.62(4.33) \\
{[69.7-73.3]}\end{array}$ & $\begin{array}{c}{[25.8-29.7]} \\
3.25(.88) \\
{[53.7-57.7]}\end{array}$ & $\begin{array}{c}{[28.4-32.3]} \\
3.23(.73) \\
{[59.8-63.7]}\end{array}$ & $\begin{array}{c}{[25.8-29.8]} \\
3.20(.80) \\
{[56.6-60.5]}\end{array}$ & $\begin{array}{c}{[35.8-39.7]} \\
7.52(.09) \\
{[82.6-86.6]}\end{array}$ \\
\hline D vs. 3-4T & ns & ns & ns & ns & ns & ns & ns & ns & ns \\
\hline D vs. OW & $<.01$ & ns & $<.05$ & ns & $<.001$ & ns & ns & ns & ns \\
\hline D vs. $N$ & $<.001$ & $<.001$ & $<.05$ & $<.001$ & $<.001$ & $<.001$ & $<.001$ & $<.001$ & $<.001$ \\
\hline 3-4T vs. OW & ns & ns & ns & ns & ns & ns & ns & ns & ns \\
\hline $3-4$ T vs. $N$ & $<.001$ & ns & ns & $<.001$ & $<.001$ & $<.001$ & $<.01$ & $<.001$ & ns \\
\hline $\begin{array}{l}\text { OW vs. N } \\
\text { Groups } \\
\text { comparisons }\end{array}$ & $\begin{array}{c}n s \\
(D=3-4 T)> \\
(O W=N)\end{array}$ & $\begin{array}{c}n s \\
(D>N)=3- \\
4 T=O W=N\end{array}$ & $\begin{array}{c}n s \\
{\left[\begin{array}{c}\mathrm{ns}>(\mathrm{OW}=\mathrm{N})] \\
=3-4 \mathrm{~T})\end{array}\right.}\end{array}$ & $\begin{array}{c}<.01 \\
(\mathrm{D}=3- \\
4 \mathrm{~T}=\mathrm{OW})>\mathrm{N}\end{array}$ & $\begin{array}{c}n s \\
(D=3-4 T)> \\
(O W=N)\end{array}$ & $\begin{array}{c}<.01 \\
(\mathrm{D}=3-4 \mathrm{~T}= \\
\mathrm{OW})>\mathrm{N}\end{array}$ & $\begin{array}{c}<.01 \\
(\mathrm{D}=3-4 \mathrm{~T}= \\
\mathrm{OW})>\mathrm{N}\end{array}$ & $\begin{array}{c}n s \\
{[(D=3-} \\
4 T>N]=O W\end{array}$ & $\begin{array}{c}n s \\
(D>N)=3- \\
4 T=O W\end{array}$ \\
\hline
\end{tabular}

Notes: $\mathrm{D}=$ daily; $3-4 \mathrm{~T}=3$ or 4 times a week; OW= once a week or less; N=Never. Values between brackets [] show $95 \%$ confidence interval. 
Table 4. Regression analyses showing prediction of happiness.

\begin{tabular}{|c|c|c|c|c|}
\hline Step & Predictor(s) & Change in $\mathbf{R}^{2}$ & Total $\mathbf{R}^{2}$ & Final Beta \\
\hline 1 & Educational level & $.03^{* *}$ & $.18^{\star \star}$ & $.08^{*}$ \\
\hline \multirow[t]{4}{*}{2} & Self-kindness & $.35^{\star * *}$ & $.62^{\star \star \star}$ & $.32^{\star \star \star}$ \\
\hline & Common Humanity & $.05^{\star \star \star}$ & $.66^{\star \star \star}$ & $.27^{\star \star \star}$ \\
\hline & Awareness & $.03^{\star \star *}$ & $.68^{\star \star \star}$ & $.18^{\star \star *}$ \\
\hline & Observe & $.01^{* *}$ & $.69^{\star *}$ & $.11^{\star \star \star}$ \\
\hline
\end{tabular}

Notes: The dependent variable is the Pemberton Happiness Index (PHI) total score.

${ }^{*} p<.05 ;{ }^{* *} p<.01 ;{ }^{* * *} p<.001$ 


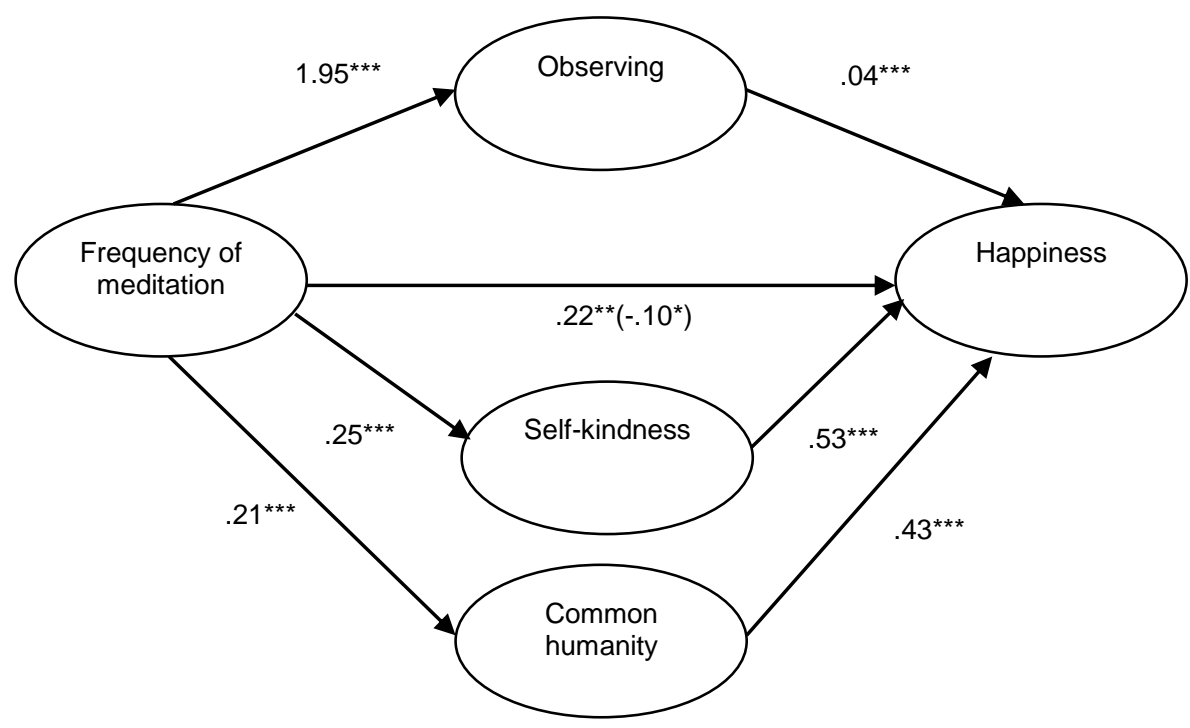

Figure 1. Relationship between frequency of meditation and happiness mediated by FFMQ and SCS facets. Note: All values are beta coefficients. The values in parentheses show the relationship between frequency of meditation and happiness when mindfulness and self-compassion subscales are included. ${ }^{*} p<.05 ;{ }^{* *} p<.01 ;{ }^{* * *} p<.001$ 